\title{
APRIMORAMENTO SOCIAL E PROFISSIONAL ENVOLVENDO ACIDENTES COM ANIMAIS PEÇONHENTOS E AS BOAS PRÁTICAS DE FABRICAÇÃO DE SOROS HIPERIMUNES*
}

Vítor Todeschini ${ }^{1}$

ORCID: https://orcid.org/0000-0002-8749-3842

Livia Matos Moreira ${ }^{2}$

ORCID: https://orcid.org/0000-0002-9683-686X

Ilana Souza Nunes ${ }^{3}$

ORCID: https://orcid.org/0000-0002-9571-7447

Rafaela C. Fegueredo 4

ORCID: https://orcid.org/0000-0001-7094-2069

Maria Gorete Carvalho da Silva Teixeira ${ }^{5}$

ORCID: https://orcid.org/0000-0002-6717-6225

Camila Braz Pereira da Costa ${ }^{6}$ ORCID: https://orcid.org/0000-0002-6926-7956

Claudio Machado ${ }^{7}$

ORCID: https://orcid.org/0000-0002-1501-1250

Arídio Mattos Junior ${ }^{8}$

ORCID: https://orcid.org/0000-0001-6478-3970

Francisco Martins Teixeira9

ORCID: https://orcid.org/0000-0003-0640-5570

Maximiliano Silva Sangoi ${ }^{10}$

ORCID: https://orcid.org/0000-0002-6009-4809

\footnotetext{
* Pesquisa financiada pelo Programa Institucional de Fomento Único de Ações de Extensão - PROFAEX da Universidade Federal do Rio de Janeiro e Instituto Vital Brazil.

${ }^{1}$ Universidade Federal do Rio de Janeiro.

${ }^{2}$ Universidade Federal do Rio de Janeiro.

${ }^{3}$ Instituto Vital Brazil.

${ }^{4}$ Instituto Vital Brazil.

${ }^{5}$ Instituto Vital Brazil.

${ }^{6}$ Instituto Vital Brazil.

${ }^{7}$ Instituto Vital Brazil.

${ }^{8}$ Universidade Federal do Rio de Janeiro.

${ }^{9}$ Universidade Federal do Rio de Janeiro.

${ }^{10}$ Universidade Federal do Rio de Janeiro.
}

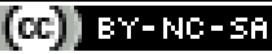

**Este é um artigo de acesso aberto distribuído sob os termos da Licença Creative Commons BY-NC-SA 4.0, que permite uso, distribuição e reprodução para fins não comercias, com a citação dos autores e da fonte original e sob a mesma licença. 
Shaft Corrêa Pinto ${ }^{11}$

ORCID: https://orcid.org/0000-0003-1540-1440

Suzana Passos Chaves ${ }^{12}$

ORCID: https://orcid.org/0000-0002-6713-9010

Thiago Barth ${ }^{13}$

ORCID: https://orcid.org/0000-0001-8534-3122

Marina Cardoso Nemitz ${ }^{14}$

ORCID: https://orcid.org/0000-0001-6226-6363

Recebido em: 26/04/2021. Publicado em:30/09/2021.

\section{RESUMO}

Os acidentes com animais peçonhentos têm importância na saúde pública, sendo fundamental ações educativas para prevenção, diagnóstico e tratamentos. No Brasil, os soros hiperimunes são preconizados para o tratamento dos acidentados. Esses produtos são produzidos por laboratórios oficiais seguindo requisitos das Boas Práticas de Fabricação (BPF) e distribuídos gratuitamente pelo Sistema Único de Saúde. Buscando atender uma demanda da sociedade, o projeto de extensão "Kaizen: Formação de recursos humanos e o aperfeiçoamento contínuo profissional, institucional e social sobre animais peçonhentos e a produção de soros na saúde pública" estabeleceu uma parceria entre o Instituto Vital Brazil (IVB) e o Curso de Farmácia da Universidade Federal do Rio de Janeiro (UFRJ-Macaé) para o desenvolvimento de ciclos de ações educativas para diferentes públicos. O primeiro ciclo foi realizado pela universidade e direcionado aos colaboradores do IVB envolvendo conteúdos das BPF. O segundo ciclo foi realizado pelo IVB para o público de Macaé e municípios limítrofes com a participação de estudantes de ensino fundamental, médio e superior, além de agentes de combate de endemias, exército brasileiro, defesa civil, centro de zoonoses e guarda ambiental. Após a realização das ações, formulários de avaliação foram fornecidos aos participantes, observando-se alto grau de satisfação. Dessa forma, as ações contribuíram para o aprimoramento do conhecimento das BPF, além de ampliar os espaços de construção do conhecimento e aprendizagem para evitar os acidentes com animais peçonhentos, assim como nos tratamentos e produção dos soros hiperimunes e distribuição na saúde pública.

Palavras-chave: animais peçonhentos; ações educativas; soros hiperimunes.

\section{SOCIAL AND PROFESSIONAL IMPROVMENT INVOLVING ACCIDENTS WITH POISONOUS ANIMALS AND GOOD MANUFACTURING PRACTICESFOR HYPERIMMUNE SERUM}

\section{ABSTRACT}

Accidents and injuries with poisonous animals have great impact on public health, thus

\footnotetext{
${ }^{11}$ Universidade Federal do Rio de aneiro.

${ }^{12}$ Universidade Federal do Rio de Janeiro.

${ }^{13}$ Universidade Federal do Rio de Janeiro.

${ }^{14}$ Universidade Federal do Rio de Janeiro.
} 
educational diagnosis and treatments are essential. In Brazil the hyperimmune serums are recommended for the treatment of the injured. These antivenom are produced by official laboratories following the Good Manufacturing Practices (GMP) requirements and distributed by the nacional Unified Health System (SUS). In order to meet a society's demand, the extension project team "Kaizen: Social, institutional and professional continuing development involving accidents with poisonous animals and the hyperimmune serum production in public health" has established a partnership between the Vital Brazil Institute and the Course of Pharmacy of Federal University of Rio de Janeiro for educational actions development for different publics. The first cycle was carried out by the University aiming at IVB employees involving GMP content. The second cycle was carried out by the IVB for Macaé and neighboring municipalities, with the participation of elementary, middle and high school students, healthcare agents to combat endemic diseases, the Brazilian army members, civil defense, zoonosis center group and environmental guard. After the actions, evaluation forms were provided to the participants to fill in with their impressions on the theme. Results showed a high overall satisfaction degree. Actions contributed to the improvement of GMP knowledge among participants, expanding the opportunity for discussion on poisonous animals accidents prevention, as well as in the treatment and production of hyperimmune serums and distribution in public health.

Keywords: educational actions; hyperimmune serums; poisonous animals.

\section{INTRODUÇÃO}

Os animais peçonhentos são aqueles capazes de injetar, através de picadas ou mordidas, substâncias tóxicas produzidas por glândulas especializadas. A injeção do veneno caracteriza-se por ser um mecanismo de caça e defesa. Estes animais podem habitar tanto meios rurais, quanto urbanos e são responsáveis por inúmeros acidentes em variadas regiões brasileiras. Alguns exemplos desses animais incluem: serpentes, aranhas, escorpiões, lacraias, taturanas, vespas, formigas, abelhas e marimbondos (BRASIL, 2009; MONACO et al., 2017). Desde a criação do Programa Nacional de Controle de Acidentes por Animais Peçonhentos (PNCAAP) em 1988, tornou-se obrigatória a realização das notificações oficiais de acidentes encaminhadas pelas secretarias estaduais de saúde à Fundação Nacional de Saúde (FUNASA) do Ministério da Saúde. Para auxiliar este procedimento adotou-se o Sistema de Informações de Agravos de Notificação (SINAN) pela Coordenação Nacional de

Controle de Zoonoses e Animais Peçonhentos (BOCHNER, STRUCHINER, 2002).

No Brasil, em 2010 foram notificados no SINAN cerca de 124 mil acidentes por animais peçonhentos e em 2014 esse número se ampliou para mais de 170 mil acidentes, sendo os mais frequentes os causados por escorpiões, serpentes, aranhas e abelhas (MACHADO, 2016). É importante mencionar que, segundo as estatísticas publicadas pelo Sistema Nacional de Informações Tóxico-Farmacológicas (SINITOX), em 2017 o somatório 
dos acidentes com animais peçonhentos (incluindo serpentes, aranhas, escorpiões e outros) foi considerado o maior índice de intoxicação no Brasil e representando 35,3\% de casos notificados (FIOCRUZ, 2020). Especificamente no estado do Rio de Janeiro, entre os anos 2009 e 2015 foram notificados mais de mil acidentes com animais peçonhentos por ano, sendo os acidentes com serpentes os de maior incidência, seguido de aranhas e escorpiões (IVANCKO, 2017).

Outra importante contribuição da PNCAAP foi o apoio para a publicação do Manual de Diagnóstico e Tratamento de Acidentes por Animais Peçonhentos (FUNASA, 2001). O manual consiste na busca de padronização das condutas de diagnóstico e tratamento dos acidentados entre as equipes de saúde, sendo a correta identificação do animal que causou o acidente bem como a avaliação dos sintomas observados fundamentais e complementares para a definição das estratégias de tratamento (FUNASA, 2001).

De uma forma geral, o principal tratamento dos acidentes com animais peçonhentos consiste na administração intravenosa dos soros contra os venenos, tais como soros antiofídicos (serpentes), antiescorpiônicos (escorpiões), antiaracnídeos (aranhas) e antiapílico (abelhas). Estes produtos são denominados soros hiperimunes e são categorizados como produtos farmacêuticos de origem biológica (equina) (BRASIL, 2017).

Para a produção de soros hiperimunes antipeçonhentos são necessárias diversas etapas que se iniciam pela obtenção do antígeno (veneno)das principais espécies de animais causadoras de acidentes em território brasileiro e sua purificação. Em seguida, um dos protocolos produtivos mais empregados é a inoculação dos antígenos em cavalos, uma vez que estes respondem bem ao estímulo e produzem uma grande quantidade de anticorpos. Após período adequado, retira-se uma quantidade de sangue do animal, purifica-se e concentra-se até a obtenção das imunoglobulinas heterólogas inteiras ou fragmentadas, resultando no produto final, o soro hiperimune antipeçonhento (CHIPPAUX; GOYFFON, 1998).

No Brasil, o Ministério da Saúde adquire os soros hiperimunes antipeçonhentos de quatro laboratórios oficiais nacionais. Dentre estes inclui-se o Instituto Vital Brazil (IVB), o qual é responsável pela produção de soros usados no tratamento de acidentes com cobras, aranhas e escorpiões (SALOMÃO, 2018). Além disso, cabe também ao Ministério da Saúde a organização e distribuição das cotas de antivenenos aos Estados conforme o Programa Nacional de Imunizações (PNI), levando em consideração critérios epidemiológicos, que são as notificações de acidentes por animais peçonhentos no SINAN (SOUZA, 2018). 
Todas as empresas produtoras de Soros Hiperimunes devem ser certificadas e cumprir as Boas Práticas de Fabricação (BPF) descritas na resolução RDC nº 301/2019 da Agência Nacional de Vigilância Sanitária (ANVISA) e registrar seus produtos segundo a resolução RDC $\mathrm{n}^{\circ}$ 187/2017 da mesma agência reguladora (BRASIL, 2017; BRASIL, 2019). Dentre os diversos requisitos das BPF seguidos pela empresa fabricante incluem-se a adequabilidade das instalações, equipamentos, sistemas computadorizados e serviços, materiais, procedimentos e instruções aprovados e vigentes, assim como as estruturas de logística (BRASIL, 2017; BRASIL, 2019). Outro item imprescindível envolve a necessidade de pessoal qualificado e devidamente treinado. Assim, o fabricante deve treinar as pessoas envolvidas com as atividades de garantia da qualidade, produção, controle de qualidade, bem como todo pessoal cujas atividades possam interferir na qualidade do produto, mediante um programa escrito e definido. Esses treinamentos devem incluir conteúdos específicos à sua posição de trabalho, além de conteúdos básicos sobre a teoria e prática de BPF (BRASIL, 2019). Ressalta-se que tais capacitações podem ser ministradas por colaboradores internos ou por pessoal externo, devendo essas equipes de consultores serem qualificadas para os serviços de treinamento que prestam, inclusive sendo necessárias evidências da qualificação nos registros de treinamento.

Dessa forma, considerando o alto índice de acidentes com animais peçonhentos no Brasil e no estado do RJ, bem como a relevância de democratizar o conhecimento sobre o tratamento e profilaxia dos acidentes e a necessidade de melhoria contínua nos procedimentos das empresas farmacêuticas produtoras de soros hiperimunes, objetivou-se, neste trabalho, a troca de saberes entre a Universidade Federal do Rio de Janeiro - Campus Macaé (UFRJMacaé), o IVB e a comunidade de Macaé e região. Os procedimentos escolhidos para alcançar os objetivos do trabalho compreenderam as etapas de desenvolvimento, aplicação e avaliação de ciclos de ações educativas contemplando temáticas de interesse voltadas para cada tipo de público-alvo.

\section{METODOLOGIA}

Este trabalho foi realizado pela equipe do projeto de extensão intitulado "Kaizen: Formação de recursos humanos e o aperfeiçoamento contínuo profissional, institucional e social sobre animais peçonhentos e a produção de soros na saúde pública”, formada por integrantes do Curso de Farmácia da UFRJ-Macaé e integrantes do Centro de Estudo e Aperfeiçoamento (CEA) do IVB. 
Considerando as diretrizes da Interação Dialógica entre a Universidade e os setores sociais, foram realizadas ações educativas durante os anos de 2018 e 2019 para diferentes públicos-alvo nas dependências do IVB, localizado na Rua Maestro José Botelho, 64, bairro Vital Brasil - Niterói-RJ e nas dependências do polo universitário da UFRJ-Macaé, localizado na Avenida Aluízio da Silva Gomes, 50, bairro Novo Cavaleiros - Macaé-RJ. As ações educativas nas dependências da empresa foram desenvolvidas pelos docentes da UFRJ-Macaé, integrantes do projeto de extensão e envolveram conteúdos básicos sobre as BPF e gestão da qualidade, sendo aplicadas para todo corpo funcional do IVB. As ações educativas nas dependências do polo universitário, por sua vez, foram desenvolvidas por colaboradores do IVB, estando relacionados à prevenção, notificações, cuidados e tratamento de acidentes com animais peçonhentos e tendo como público-alvo a comunidade escolar de Macaé e região e profissionais atuantes no combate de endemias, exército brasileiro, defesa civil, centro de zoonoses e guarda ambiental do município.

Ambas as ações foram desenvolvidas considerando as etapas de definição das necessidades, planejamento, execução e avaliação dos resultados em convergência às etapas do ciclo metodológico PDCA (Plan-Do-Check-Action) e à norma NBR ISO 10015 da Associação Brasileira de Normas Técnicas (ABNT) referentes às diretrizes para treinamentos (ABNT, 2001). Para a etapa de planejamento das ações, a equipe executiva do projeto de extensão fez a utilização da ferramenta de gestão $5 \mathrm{~W} 2 \mathrm{H}$ que consiste em conhecer o que será feito, quais as etapas do processo (What), por que será realizado, a sua justificativa (Why), onde (Where), quando será efetivado, limitar e prever o tempo (When), quem executará os procedimentos (Who), como será o método (How) e por fim, qual será o custo (How much) (FREITAS, 2013).

A etapa de avaliação das ações objetivou verificar a eficácia das estratégias educativas perante os públicos envolvidos para registro e monitoramento, sendo subsídio para a melhoria contínua de intervenções futuras. Para tal, um formulário de satisfação foi elaborado e disponibilizado ao final das atividades tanto nas dependências da empresa quanto nas dependências da universidade, sendo de preenchimento voluntário e anônimo. $\mathrm{O}$ formulário foi composto por diferentes itens de avaliação, os participantes poderiam sinalizar se o nível de satisfação era de Péssimo, Ruim, Regular, Bom ou Ótimo. Para o item "Infraestrutura e logística" foram analisados o nível de satisfação em relação à Equipe organizadora, Pontualidade, Adequação de carga horária, Instalações e ambiente e Material didático. Para o item "Instrutor" foram analisados o nível de satisfação em relação ao Domínio do assunto, 
Facilidade e objetividade na comunicação, Capacidade de esclarecer dúvidas, Cumprimento dos horários e Cumprimento do conteúdo programático. Já para o item "Treinando" foram analisados o nível de satisfação em relação a Facilidade de entendimento dos assuntos abordados, Aquisição de novos conhecimentos e Capacidade de transmitir o conteúdo a outros, além dos espaços reservados à comentários adicionais, pontos positivos e negativos e sugestões de melhoria. Como este formulário caracteriza uma pesquisa de satisfação, não foi necessário o registro e avaliação do formulário pelo sistema Comitê de Ética em Pesquisa/Comissão Nacional de Ética em Pesquisa (CEP/CONEP) conforme destacado na resolução que dispõe sobre as normas aplicáveis a pesquisas em Ciências Humanas e Sociais (BRASIL, 2016).

\section{RESULTADOS E DISCUSSÃO}

\subsection{Ações educativas nas dependências da empresa}

Definiu-se que as atividades educativas seriam intituladas de "Ciclo de capacitação em gestão da qualidade" e seriam baseadas nos conceitos de gestão da qualidade e nas diretrizes das BPF. Assim, discutiu-se a importância da participação coletiva no atendimento as especificações dos clientes internos e externos, conceituando os principais requisitos das BPF relacionados a pessoal, infraestrutura e documentação, com ênfase nos procedimentos operacionais padrão como importante estratégia para garantir reprodutibilidade e nos registros objetivando a rastreabilidade das atividades de rotina, assim como na importância das auditorias internas periódicas nas ações de melhoria contínua. Vale destacar que estas práticas são adequadamente disseminadas na empresa, mas são fundamentais no processo de educação continuada e melhoramento permanente previsto nos sistemas de qualidade. O planejamento do ciclo de capacitação considerou a aplicação da ferramenta $5 \mathrm{~W} 2 \mathrm{H}$, conforme apresentado na Tabela 1. 
Tabela 1. Ferramenta 5W2H aplicada ao planejamento das atividades educativas nas dependências da empresa.

\begin{tabular}{l|l}
\hline ETAPAS DO 5W2H & DESCRIÇÃO DA ATIVIDADE \\
\hline What (o que?) & Realização de ciclo de capacitação \\
Why (por quê?) & Requisito compulsório das BPF e necessidade de melhoramento contínuo \\
Where (onde?) & Auditório do Instituto Vital Brazil em Niterói-RJ \\
When (quando?) & De setembro de 2018 a junho de 2019 \\
Who (quem?) & $\begin{array}{l}\text { Ministrados pelos professores da equipe do projeto Kaizen do Curso de } \\
\text { Farmácia da UFRJ-Macaé }\end{array}$ \\
How (como?) & $\begin{array}{l}\text { Através de palestras expositivas e dialogadas } \\
\text { Não há custo direto, uma vez que a parceria estabelecida entre as instituições } \\
\text { How much (quanto?) }\end{array}$ \\
\hline
\end{tabular}

Fontes: elaborado pelos autores

O ciclo de capacitação foi organizado durante 1 ano entre o período de junho de 2018 a junho de 2019, com 12 turmas e uma média de 30 colaboradores por turma. As palestras expositivas e dialogadas foram estruturadas com 2 horas de duração e o cronograma ajustado entre as partes envolvidas. Assim, uma vez definida as datas dos encontros presenciais, os colaboradores do IVB foram então convocados conforme escala definida pelo CEA e gestores das áreas, de forma que nenhum processo empresarial fosse paralisado por conta das atividades.

Nos dias pré-determinados para execução das ações, o palestrante do Curso de Farmácia da UFRJ-Macaé foi recebido nas dependências do IVB e, após chegada dos colaboradores e breve apresentação, deu-se o início da atividade. Ressalta-se que as capacitações foram executadas de modo dinâmico, dialogado e interativo, dentro do prazo de 2 horas previsto por turma, sendo que em cada dia de atividade foram capacitadas duas turmas (uma no turno da manhã e uma no turno da tarde). Assim, participaram do ciclo de capacitação o total de 12 turmas, com uma média de 26,6 participantes por turma e totalizando 319 pessoas (turmas 1 e 2 no dia 12/09/2018 - 32 e 29 participantes, respectivamente; turmas 3 e 4 no dia 10/10/2018 26 e 34 participantes, respectivamente; turmas 5 e 6 no dia 07/11/2018 - 22 e 27 participantes, respectivamente; turmas 7 e 8 no dia

24/04/2019, ambas com 27 participantes; turmas 9 e 10 no dia 03/07/2019 - 31 e 26 participantes, respectivamente; turmas 11 e 12 no dia 18/09/2019 - 18 e 20 participantes, respectivamente). 
O número atingido de participantes corresponde a $85,3 \%$ do total de colaboradores do IVB da época. Cabe mencionar que 8,8\% dos colaboradores da empresa se ausentaram devido a demandas que sobrepuseram o horário das ações educativas, além da ausência dos colaboradores portadores de deficiências que necessitariam adaptações dos conteúdos e participação de intérprete. Esse público representava 5,8\% dos colaboradores da empresa. A Figura $1(\mathrm{a}, \mathrm{b}, \mathrm{c})$ apresenta imagens das atividades educativas realizadas nas dependências do IVB.

Figura 1 - Imagens nas dependências da empresa: (a) Visita da equipe do Projeto Kaizen e (b,c) Atividades educativas. Imagens nas dependências do polo universitário UFRJ-Macaé, (d) Minicurso de produção de soros hiperimunes, (e) Minicurso de manejo de animais peçonhentos, (f) Minicurso de serpentes de importância médica e (g,h,i) Atividade "Exposição de animais peçonhentos"
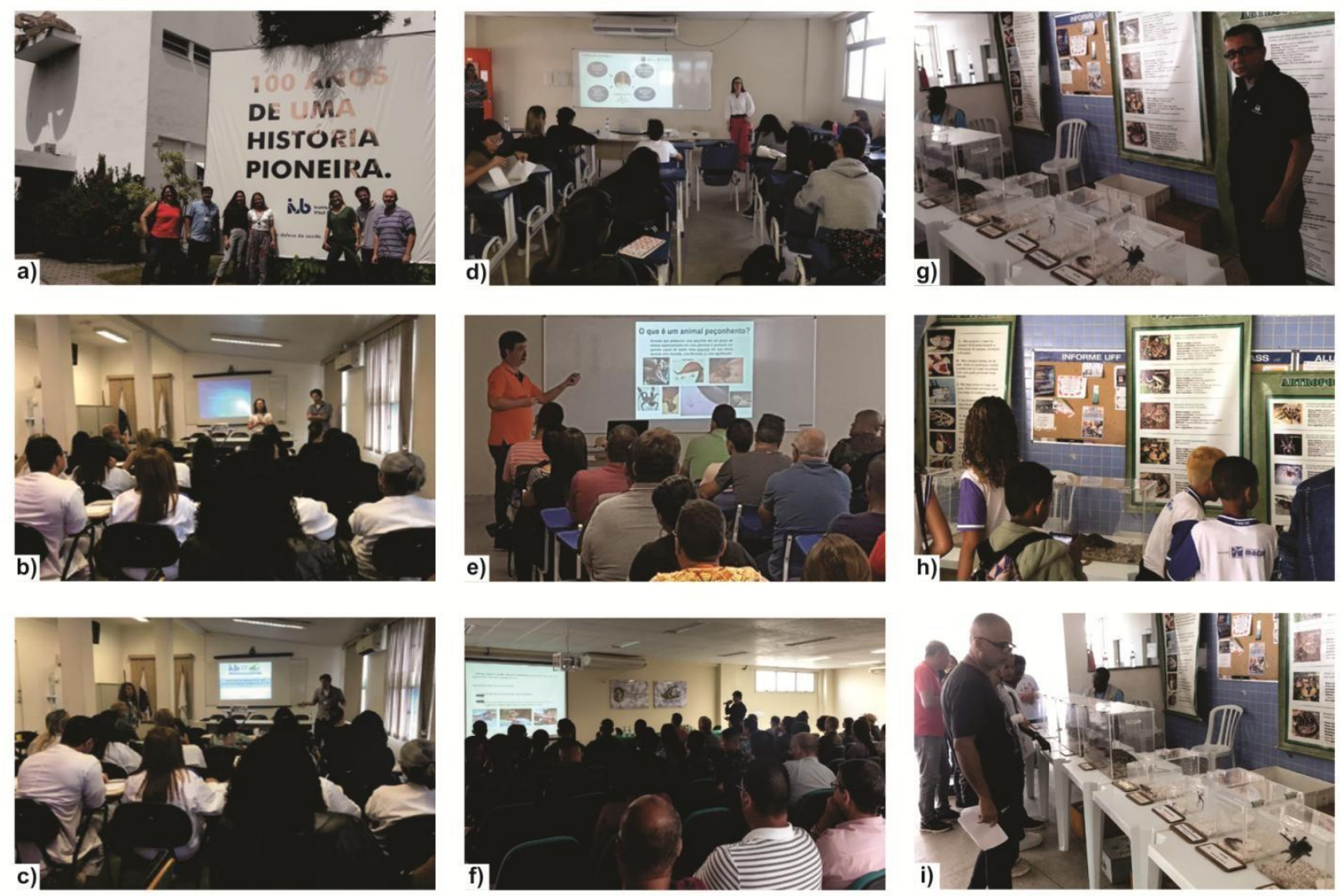

Fonte: Elaborado pelos autores.

Além da emissão de declarações de participação, ao término das atividades foi aplicada uma breve avaliação de satisfação junto ao público participante. Esta avaliação foi realizada através do preenchimento de um formulário com alternativas de Péssimo, Ruim, Regular, Bom e Ótimo para os itens de Infraestrutura e Logística, Instrutor e Treinando. Dos 317 participantes nas 12 turmas de atividades, $90 \%$ responderam ao questionário, sendo o percentual de respostas 
em cada item avaliado nos formulários representadas na Figura 2 (a,b,c).

Figura 2 - Resultado das avaliações das atividades educativas nas dependências do IVB: (a) Infraestrutura e Logística, (b) Instrutor e (c) Treinando. Resultado das avaliações das atividades educativas nas dependências do polo universitário UFRJ-Macaé: (d) Infraestrutura e Logística, (e) Instrutor e (f) Treinando
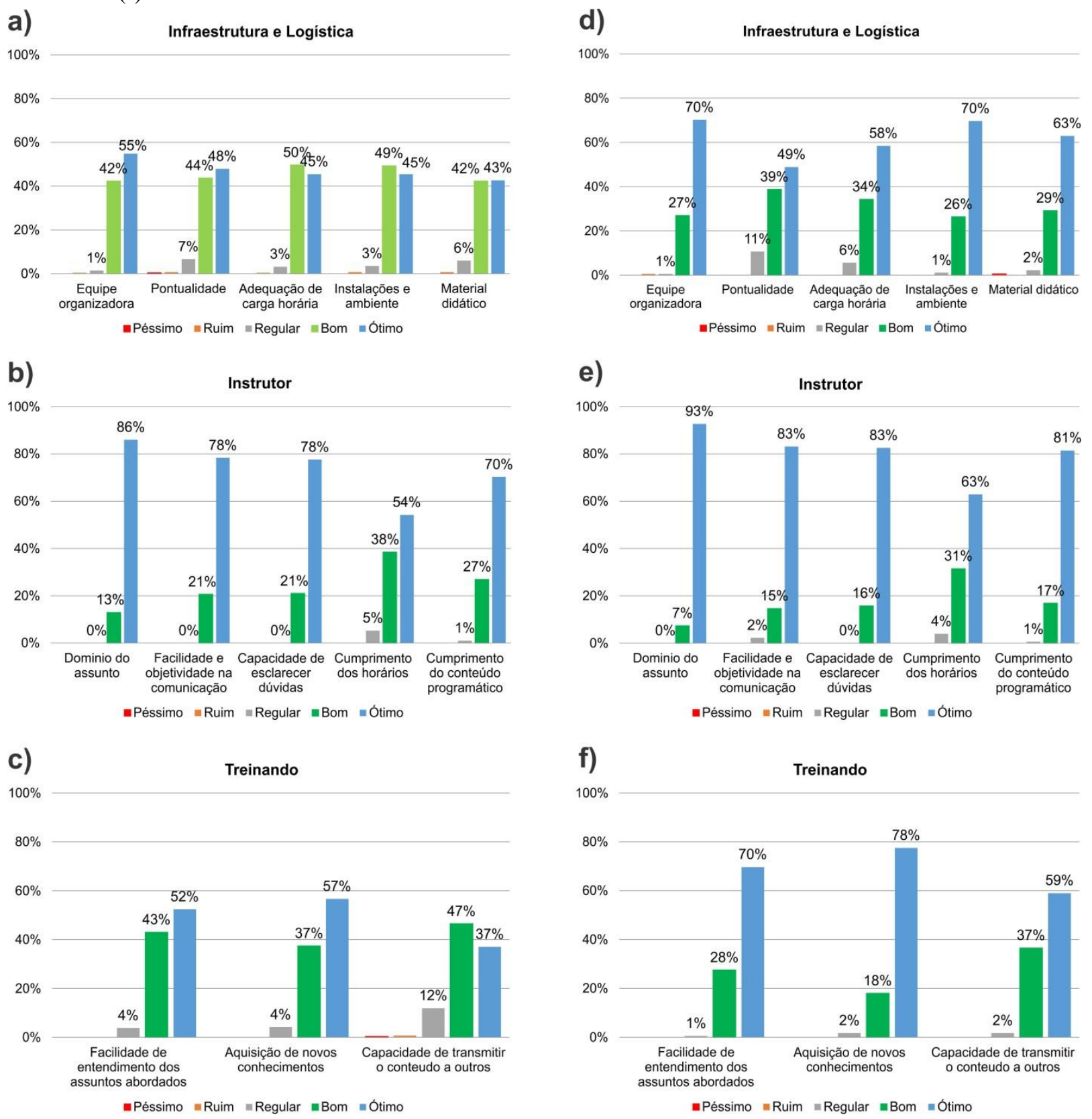

Fonte: Elaborado pelos autores.

As respostas obtidas de cada colaborador em cada item avaliado nos formulários foram consolidas em planilha de dados e analisadas em relação ao percentual total de formulários entregues por todas as turmas participantes. Conforme pode ser observado na Figura 2, os valores obtidos nos formulários de avaliação demonstram relevante desempenho das atividades em todas as turmas. As respostas dos itens avaliados em relação à Infraestrutura e Logística 
apresentam importantes evidências de satisfação do público com percentual de $93 \%$ entre Ótimo e Bom, não havendo indicações avaliações péssimas. Na avaliação do Instrutor, as respostas dos itens avaliados evidenciaram desempenho ainda melhor, apresentando 97\% de respostas entre Ótimo e Bom. Já na avaliação do Treinando, por sua vez, as respostas foram de 93\% entre Ótimo e Bom, sem indicações ruins e péssimas.

Além dos dados quantitativos, o formulário fornecia campo de preenchimento para comentários, sendo observados comentários essencialmente positivos. Do ponto de vista dos treinandos, a pontualidade é item fundamental e pode ser ajustado com mudanças na modalidade de transporte dos palestrantes até as dependências da empresa, minimizando dificuldades de trânsito ou através do uso de ferramentas virtuais remotas. Ressalta-se que esta modalidade vem sendo discutida para continuidade das atividades do projeto, podendo apresentar vantagens relacionadas a movimentação dos participantes e até a gravação e disponibilização assíncrona da capacitação para estudo posterior por parte dos envolvidos. Adicionalmente algumas sugestões foram feitas, como treinamentos sobre boas práticas de documentação e de armazenamento e transporte, não-conformidades, ferramentas da qualidade, análise de risco. Alguns pontos levantados foram a duração do treinamento que poderia ser fragmentado, ser estruturado com atividades práticas, além de diversos relatos parabenizando a didática do instrutor e parceria entre as instituições.

Logo após a finalização do ciclo de capacitação, a equipe do projeto avaliou os resultados e ponderou sobre as possíveis melhorias visando a perspectiva de continuidade das ações educativas na empresa por parte dos professores da UFRJ-Macaé. Foi discutida a dificuldade relacionada à movimentação de Macaé à Niterói. Alternativa importante seria a disponibilidade de veículo exclusivo por parte da UFRJ para este deslocamento, ou ainda, adotar o ensino à distância, desenvolvendo conteúdos e atividades síncronas e assíncronas através do uso de Ambiente Virtual de Aprendizagem (AVA) e serviços de comunicação por vídeo, limitando os deslocamentos ao máximo possível, principalmente entre cidades de tráfego tumultuado. Outra proposta discutida foi a definição de conteúdos específicos para os setores empresariais, assim como o desenvolvimento e aplicação de questionários para mensurar o impacto do treinamento na rotina de trabalho dos colaboradores. Uma vez desenvolvido esse futuro instrumento de pesquisa, será fundamental a validação do mesmo. Para tal, voluntários avaliarão os conteúdos, estrutura, escrita, pertinência e objetividade do instrumento e suas impressões serão base para a melhoria do mesmo, garantindo a confiabilidade e credibilidade das informações obtidas e minimizando os prejuízos e dúvidas 
nas respostas.

\subsection{Ações educativas nas dependências do polo universitário}

Definiu-se que as atividades educativas no polo universitário seriam conduzidas durante a Semana Nacional de Ciência e Tecnologia (SNCT) e Semana de Integração Acadêmica (SIAC) do Campus UFRJ-Macaé de 2019 e envolveriam a exposição itinerante de animais peçonhentos do IVB juntamente com painéis apresentando curiosidades e dúvidas frequentes, assim como a realização de 3 minicursos focados em públicos diferentes. Da mesma forma que as ações educativas realizadas na empresa, o planejamento das ações também foi organizado com a aplicação da ferramenta da qualidade 5W2H conforme apresentado na Tabela 2.

Tabela 2 - Ferramenta 5W2H aplicada ao planejamento das atividades educativas nas dependências do polo universitário

\begin{tabular}{l|l}
\hline ETAPAS DO 5W2H & DESCRIÇÃO DA ATIVIDADE \\
\hline What (o que?) & $\begin{array}{l}\text { Realização das atividades educativas envolvendo acidentes com animais } \\
\text { peçonhentos, cuidados e tratamentos } \\
\text { Importância para a saúde pública } \\
\text { Em salas de aula e ambiente comum do polo universitário da UFRJ-Campus } \\
\text { Macaé }\end{array}$ \\
Where (onde?) & $\begin{array}{l}\text { De } 21 \text { a } 27 \text { de outubro de } 2019 \\
\text { Equipe de colaboradores do Instituto Vital Brazil } \\
\text { When (quando?) }\end{array}$ \\
Who (quem?) & $\begin{array}{l}\text { Através de palestras expositivas e dialogadas e exposição de animais } \\
\text { peçontos }\end{array}$ \\
How (como?) & $\begin{array}{l}\text { Náo custo direto, uma vez que a parceria estabelecida entre as instituições } \\
\text { envolve a troca de saberes e ações extensionistas }\end{array}$ \\
How much (quanto?)
\end{tabular}

Fonte: Elaborado pelos autores.

O minicurso intitulado "Produção de soros hiperimunes no Instituto Vital Brazil (IVB)" foi estruturado para ocorrer no período da manhã do dia 22 de outubro de 2019, carga horária de 3 horas e tendo como público-alvo essencialmente os alunos do Curso de Farmácia da UFRJCampus Macaé. O curso intitulado "Manejo de animais peçonhentos”, por sua vez, foi estruturado para ocorrer no período da tarde do dia 22 de outubro de 2019 e perfazendo a carga horária de 3 horas. O público-alvo foi profissionais das mais diferentes esferas de Macaé que podem ter contato com animais peçonhentos, incluindo os agentes de combate às endemias, exército brasileiro, defesa civil, centro de zoonoses e guarda ambiental. Já o minicurso intitulado “Serpentes de importância médica” foi idealizado para o período da manhã do dia 23 de outubro 
de 2019. A carga horária prevista foi de 3 horas, tendo o mesmo público-alvo anteriormente descrito para o minicurso de manejo, além da comunidade acadêmica de forma geral, principalmente os estudantes de medicina, enfermagem e farmácia. O público de alunos e profissionais foram convidados presencialmente e com entrega impressa da programação, além do uso de aplicativos de telefone e email. Além dos minicursos, a atividade intitulada "Exposição de animais peçonhentos ”, foi também organizada para realização nos dias 22 e 23 de outubro de 2019, perfazendo a carga horária total de 6 horas, sendo aberta a toda a comunidade e alunos do ensino fundamental, médio e superior que estavam participando da SNCT.

Os minicursos foram conduzidos em espaços contendo infraestrutura audiovisual e climatização pertinente, enquanto a exposição de animais peçonhentos contou com infraestrutura necessária para a segurança das pessoas e dos animais expostos conforme orientação do IVB. Cartazes orientativos foram usados para direcionar os públicos participantes aos respectivos ambientes.

O minicurso intitulado "Produção de soros hiperimunes no Instituto Vital Brazil (IVB)" discutiu as diferentes etapas de obtenção do produto farmacêutico, desde a matéria-prima, produção e envase, tendo um total de público de 54 participantes. O curso intitulado "Manejo de animais peçonhentos" abordou assuntos relacionados aos cuidados, sintomas e formas de manejo de animais peçonhentos, inclusive com a realização de extração de veneno, a matéria- prima para os soros hiperimunes e teve um total de 68 participantes. O minicurso intitulado "Serpentes de importância médica” apresentou as principais serpentes no Brasil, as formas de acidentes, sintomas e possibilidades de tratamentos e teve um total de 102 participantes. A Figura 1 (d, e, f) apresenta imagens dos minicursos realizados nas dependências do polo universitário.

Conforme anteriormente relatado, paralelamente aos minicursos ocorreu a atividade intitulada "Exposição de animais peçonhentos". Juntamente com outras ações da SNCT, essa atividade manteve-se aberta e com livre acesso a toda a comunidade e alunos de ensino fundamental, médio e superior participantes SNCT que contou com aproximadamente 730 alunos de escolas de ensino fundamental e médio. A Tabela 3 e Figura 1 (g, h, i) apresentam os detalhamentos dos participantes da atividade e imagens da exposição, respectivamente. 
Tabela 3 - Escolas participantes da SNCT 2019 nas dependências do polo universitário

\begin{tabular}{|c|c|c|}
\hline ESCOLA & MUNICÍPIO & ENSINO \\
\hline Centro Educacional São Francisco & Conceição de Macabu & Médio \\
\hline Centro Educacional Batista & Casimiro de Abreu & Médio \\
\hline Colégio de Aplicação - CAP Macaé & Macaé & Médio \\
\hline C. E. Prof ${ }^{\mathrm{a}}$ Vanilde Natalino Mattos & Macaé & Médio \\
\hline Alternativa Colégio & Rio das Ostras & Médio \\
\hline Colégio Castelo & Macaé & Médio \\
\hline Escola Municipal Neusa Goulart Brizola & Macaé & Fundamental \\
\hline C. E. $1^{\circ}$ de Maio & Macaé & Médio \\
\hline C. E. Jornalista Álvaro Bastos & Macaé & Médio \\
\hline CIEP José Bonifácio Tassara & Conceição de Macabu & Médio \\
\hline C. E. Jacyntho Xavier Martins & Rio das Ostras & Médio \\
\hline Colégio RH Positivo - Bahiense & Rio das Ostras & Médio \\
\hline VIVA - RIO / Unidade Macaé & Macaé & Jovem Aprendiz \\
\hline Unidade de Ensino SESI/SENAI & Macaé & Médio \\
\hline
\end{tabular}

Fonte: Elaborado pelos autores.

Da mesma forma que as atividades educativas nas dependências da empresa, ao término dos minicursos foi entregue a avaliação de satisfação ao público participante. Dos 224 participantes dos três minicursos, $79 \%$ responderam ao questionário, sendo o percentual de respostas em cada item avaliado nos formulários representados na Figura 2 (d, e, f).

As respostas obtidas nos formulários também foram consolidas em planilha de dados e analisadas em relação ao percentual total de formulários entregues pelos participantes. Conforme pode ser observado, as ações educativas receberam ótima avaliação em todos os itens de Infraestrutura e Logística, Instrutor e Treinando. As respostas dos itens de Infraestrutura e Logística obtiveram percentual de todos os itens avaliados de 93\% entre Ótimo e Bom, evidenciando a satisfação do público em relação à equipe organizadora, pontualidade, adequação de carga horária, instalações e ambiente e material didático. $\mathrm{Na}$ avaliação do Instrutor, por sua vez, as respostas de todos os itens avaliados apresentaram percentual geral de 98\% entre Ótimo e Bom, demonstrando o domínio do assunto, facilidade e objetividade na comunicação, capacidade de esclarecer dúvidas, cumprimento dos horários e do conteúdo programático por parte dos instrutores. Já na parte do formulário destinada a avaliação do Treinando, as respostas de todos os itens avaliados obtiveram percentual geral de $97 \%$ entre Ótimo e Bom, caracterizando a facilidade de entendimento dos assuntos abordados, aquisição de novos conhecimentos e capacidade de transmitir o conteúdo a outros por parte 
dos participantes.

Esses valores demonstram o importante desempenho das atividades nos minicursos. Além dos dados quantitativos, no campo de observações foram observados comentários essencialmente positivos. Os poucos pontos negativos estavam relacionados ao café oferecido, o pequeno tempo de intervalo e a repetição de conteúdos nos minicursos. É importante ressaltar que, a atividade "Exposição de animais peçonhentos" envolveu um dinâmica que impossibilitava empregar questionário.

Após a finalização das ações foi realizada uma reunião entre a equipe para avaliação das ações e perspectivas para continuidade futura. A percepção da equipe executora durante o relacionamento com o público-alvo evidenciou a importância da temática abordada, especialmente pelos relatos de conceitos e condutas inadequadas envolvendo animais peçonhentos que fazem parte do conhecimento popular e sobre o desconhecimento relacionado à conduta de tratamentos e localidades das unidades de saúde que possuem os recursos para tal. Além disso, percebeu-se a imensa curiosidade e interesse por parte do público sobre a temática, uma vez que os animais peçonhentos fazem parte do imaginário e do cotidiano de diversos públicos.

Nesse contexto, foi considerada a possibilidade de efetuar periodicamente o ciclo de palestras na universidade em eventos extencionistas abertos a população, buscando a ampliação para públicos específicos como produtores rurais, agentes de limpeza urbana, profissionais da saúde, entre outros. Outra possibilidade de continuidade apontada foi relacionada a palestras específicas sobre as demais categorias de animais peçonhentos (aranhas e escorpiões) e o uso de ferramentas virtuais com transmissões ao vivo em redes sociais por exemplo.

\section{CONCLUSÕES}

A educação continuada é fundamental na melhoria de desempenho das organizações e promoção de conhecimento, sendo fundamental o incentivo e a execução de ações de aprimoramento contínuo nas diversas esferas da sociedade. Nesse contexto, a extensão universitária, reconhecida como um pilar das universidades, é de extrema importância na condução de projetos, ações e atividades para essa finalidade.

O presente trabalho descreve uma importante contribuição do projeto Kaisen para a sociedade, uma vez que participou da melhoria contínua de uma empresa farmacêutica 
produtora de soros hiperimunes perante as normativas de BPF, bem como a troca de saberes com a comunidade de Macaé e região sobre os tratamentos, manejo e profilaxia de acidentes com animais peçonhentos.

Além dos altos níveis de satisfação observados pelas fichas de avaliações das ações educativas, houve grande participação e alcance dos diferentes públicos, permitindo a integração dos profissionais, acadêmicos, funcionários da empresa e comunidade regional. Assim, estabeleceu-se um importante canal de comunicação entre as instituições e a sociedade, contribuindo para a formação profissional, intelectual e social, permitindo difundir o conhecimento sobre cuidados e alternativas envolvendo acidentes com animais peçonhentos.

\section{AGRADECIMENTOS}

Os autores agradecem o Programa Institucional de Fomento Único de Ações de Extensão (PROFAEX) da UFRJ e o Instituto Vital Brazil (IVB).

\section{REFERÊNCIAS}

AGÊNCIA NACIONAL DE VIGILÂNCIA SANITÁRIA. Resolução de Diretoria Colegiada $n^{\circ} 301$, de 21 de agosto de 2019. Dispõe sobre as boas práticas de fabricação de medicamentos. Diário Oficial da União. 22 ago. 2019.

AGÊNCIA NACIONAL DE VIGILÂNCIA SANITÁRIA. Resolução de Diretoria Colegiada $n^{\circ} 187$, de 8 de novembro de 2017. Dispõe sobre o registro de Soros Hiperimunese dá outras providências. Diário Oficial da União. 09 nov.2017.

ASSOCIACAO BRASILEIRA DE NORMAS TECNICAS. NBR ISO 10015: Gestão da qualidade: Diretrizes para treinamento. Rio de Janeiro, 2001.

BRASIL. Ministério da Saúde. Secretaria de Atenção à Saúde. Departamento de Atenção Básica. Vigilância em saúde: Zoonoses. Cadernos de Atenção Básica, n. 22. - Brasília: Ministério da Saúde, 2009.

BRASIL. Conselho Nacional de Saúde. Resolução n 510 , de 7 de abril de 2016. Dispõe sobre as normas aplicáveis a pesquisas em Ciências Humanas e Sociais cujos procedimentos metodológicos envolvam a utilização de dados diretamente obtidos com os participantes ou de informações identificáveis ou que possam acarretar riscos maiores do que os existentes na vida cotidiana. Diário Oficial da República Federativa do Brasil, Brasília, DF, 2016.

BRASIL. Agência Nacional de Vigilância Sanitária. Resolução nº 187, de 8 de novembro de 2017. Dispõe sobre o registro de Soros Hiperimunes e dá outras providências. Diário Oficial da República Federativa do Brasil, Brasília, DF, 2017. 
BRASIL. Agência Nacional de Vigilância Sanitária. Resolução no 301, de 21 de Agosto de 2019. Dispõe sobre as Boas Práticas de Fabricação de Medicamentos. Diário Oficial da República Federativa do Brasil, Brasília, DF, 2019.

BOCHNER, Rosany; STRUCHINER, Cláudio José. Acidentes por animais peçonhentos e sistemas nacionais de informação. Cadernos de Saúde Pública, v.18, n. 3, p. 735-746, 2002.

CHIPPAUX, Jean-Philippe; GOYFFON, Max. Venoms, antivenoms and immunotherapy.

Toxicon, v. 36, n. 6, p. 823-846, 1998.

FIOCRUZ - Fundação Oswaldo Cruz/Centro de Informação Científica e Tecnológica/Sistema Nacional de Informações Tóxico-Farmacológicas. Estatística Anual de Casos de Intoxicação e Envenenamento. Disponível em: https://sinitox.icict.fiocruz.br/sites/sinitox.icict.fiocruz.br/files//Brasil3_1.pdf. Acesso em: 05 ago. 2020.

FREITAS, Paulo Roberto Castro; PIRES, Mariel Rosana; SANTOS Leandro Dorneles; FAGUNDES, Jair Antonio; POLACINSKIL, Edio. Ferramentas gerenciais da qualidade: um modelo para solução de problemas organizacionais. Disciplinarum Scientia. Série: Sociais e Aplicadas, Santa Maria, v. 9, n. 1, p. 43-57, 2013.

FUNDAÇÃO NACIONAL DE SAÚDE. Manual de diagnóstico e tratamento de acidentes por animais peçonhentos. 2. ed. Brasilia: Fundação Nacional de Saúde, FUNASA. 2001.

IVANCKO, Cristina Araújo. Ouvidoria do Instituto Vital Brazil: Canal capaz de captar a problemática de acidentes por animais peçonhentos no Estado do Rio de Janeiro. Dissertação (Mestrado) - Instituto de Comunicação e Informação Científica e Tecnológica em Saúde, Pós-Graduação em Informação e Comunicação em Saúde. Rio de Janeiro, 2017.

MACHADO, Cláudio. Um panorama dos acidentes por animais peçonhentos no Brasil. Journal Health NPEPS, v. 1, n. 1, p. 1-3, 2016.

MONACO, Luciana. M.; MEIRELES, Fabíola. C.; ABDULLATIF, Maria Teresa. (orgs). Animais venenosos: serpentes, anfíbios, aranhas, escorpiões, insetos e lacraias. 2.ed. São Paulo: Instituto Butantan, 2017. 40 p.

SALOMÃO, Maria da Graça; LUNA, Karla Patrícia de Oliveira; MACHADO, Cláudio. Epidemiologia dos acidentes por animais peçonhentos e a distribuição de soros: estado de arte e a situação mundial. Revista de Salud Pública, v. 20, n. 4, p. 523-529, 2018.

SOUZA, Claudio Maurício Vieira; et al. (orgs.). Livro de resumos do Seminá rio sobre Vigilância de Acidentes por Animais Peconhentos. Niterói: Instituto Vital Brazil, 2018. 